\title{
Rotulação na perspectiva do modelo dialogal da argumentação
}

\author{
Labeling from the perspective of the dialogical model of \\ argumentation
}

\author{
Nádia Vieira Simão ${ }^{1}$ \\ Rubens Damasceno-Morais ${ }^{2}$
}

Resumo: Este trabalho propõe o estudo da rotulação, a partir da retomada e antecipação, na interação argumentativa, à luz do modelo dialogal da argumentação. O objetivo é verificar se a rotulação, ao realizar os movimentos de retomada e antecipação, pode se constituir como um recurso não apenas linguístico, como também argumentativo. A ancoragem teórica parte de dois campos de estudos: a Linguística Textual e a Argumentação. A primeira com foco no processo de rotulação (FRANCIS, [1994] 2003; CONTE, [1996] 2003; CARVALHO, 2005; KOCH, 2006; 2011; ALVES JUNIOR, 2011) e a segunda a partir dos estudos do modelo dialogal da argumentação (PLANTIN, 2008; 2018; GRÁCIO, 2010; 2012; 2013; DAMASCENO-MORAIS, 2017; 2020; 2021). Além dessas duas perspectivas teóricas principais, foram mobilizados alguns pressupostos da Análise Conversacional (SACKS; SCHEGLOFF; JEFFERSON, 1974; KERBRATORECCHIONI, 2006; MARCUSCHI, [1986] 2003; KERBRAT-ORECCHIONI; PLANTIN, 1995; FÁVERO et al., 2010) assimilados e adaptados pela perspectiva dialogal da argumentação. O breve corpus selecionado para é constituído por um recorte da entrevista com Ricardo Salles realizada pelo programa televisivo Roda Viva, em 2019. A descrição e análise da entrevista, a partir de uma abordagem qualitativa, lança mão de preceitos do modelo dialogal para proporcionar um recorte original de análise, como proposto pela presente chamada à publicação. A partir da empreitada analítica ora apresentada, observou-se ostensiva relação entre a retomada e a antecipação com o surgimento da estase argumentativa na interação entre entrevistado e entrevistadores do programa Roda Viva.

Palavras-chave: Rotulação. Interação argumentativa. Estase. Roda Viva. Entrevista.

Abstract: This work proposes the study of the labeling, from the resumption and anticipation, in the argumentative interaction. The objective is to verify if the labeling, when performing the movements of resumption and anticipation, can be constituted as a resource not only linguistic, but also argumentative. The theoretical approach starts from two different fields of study: Textual Linguistics and Argumentation. The first focusing on the labeling process (FRANCIS, [1994] 2003; CONTE, [1996] 2003; CARVALHO, 2005; KOCH, 2006; 2011; ALVES JUNIOR, 2011) and the second from studies of the dialogical perspective of argumentation (PLANTIN, 2008; 2018; GRÁCIO, 2010; 2012; 2013; DAMASCENOMORAIS, 2017; 2020; 2021). In addition to these two main theoretical perspectives, some assumptions of Conversational Analysis were mobilized (SACKS; SCHEGLOFF; JEFFERSON, 1974; KERBRATORECCHIONI, 2006; MARCUSCHI, [1986] 2003; KERBRAT-ORECCHIONI; PLANTIN, 1995; FÁVERO et al., 2010) assimilated and adapted by dialogical theory. The corpus of this research consists of an excerpt from the interview with Ricardo Salles conducted by the television program Roda Viva. The study follows a qualitative analysis, with an interpretive basis, based on the data obtained, we

\footnotetext{
${ }^{1}$ Universidade Federal de Goiás, Faculdade de Letras, Programa de Pós-Graduação em Letras e Linguística, Goiânia, GO, Brasil. Endereço eletrônico: nadiavieira44@gmail.com.

${ }^{2}$ Universidade Federal de Goiás, Faculdade de Letras, Programa de Pós-Graduação em Letras e Linguística, Goiânia, GO, Brasil. Endereço eletrônico: damasceno.morais@ufg.br.
} 
observed a relationship between the resumption and the anticipation with the emergence of stasis in the argumentative interaction.

Keywords: Lettering. Argumentative interaction. Stasis. Live Wheel. Interview.

\section{Considerações iniciais: mapeamento de pesquisas e entrecruzamentos teóricos}

$\mathrm{O}$ estudo ora apresentado figura-se como um pequeno recorte de um estudo maior que buscou compreender a relação existente entre o processo referencial de rotulação com a interação argumentativa, a partir de preceitos do modelo dialogal da argumentação. Assim, aqui apresentaremos duas das funções exercidas pelos rótulos, a retomada e a antecipação, com o objetivo de verificar se elas interferem na interação argumentativa que se desenvolve entre os interactantes na entrevista do programa televisivo Roda Viva.

Considerando esses fatores, construímos a seguinte problemática que procuramos responder ao longo do texto: As funções de retomada e antecipação realizadas pelo processo de rotulação participam da construção da interação argumentativa no programa de entrevista Roda Viva? Para tentar responder a essa questão, o estudo aqui desenvolvido tomou por base dois campos de estudos diferentes, a Linguística Textual - com o foco no processo de rotulação -, e a Argumentação -, a partir dos estudos do modelo dialogal da argumentação; além de alguns pressupostos da Análise Conversacional.

A definição do recorte teórico impactou diretamente a escolha do corpus. O programa televisivo Roda Viva despertou interesse por apresentar questões importantes em voga a serem debatidas, evidenciando a relevância da realização de debates sobre temas de interesse geral, até mesmo polêmicos, mas que contribuem para a construção de uma sociedade mais crítica e reflexiva. Certamente, descrever e refletir sobre a forma como se debate em um programa de grande audiência é um fator de extrema relevância em um país como o Brasil, que se consolida a partir de um regime democrata pautado pelas escolhas dos cidadãos. A partir dessa relação de debate presente nas entrevistas realizadas pelo Roda Viva, foi considerado interessante analisar esse aspecto a partir do modelo dialogal da argumentação, por se tratar, justamente, de uma situação de interação com alto teor argumentativo.

Outro fator determinante para a escolha dessa teoria foi que, após uma ampliação na busca por estudos e pesquisas que trouxessem essa interligação entre rotulação e a argumentação em perspectiva dialogal, foram encontrados poucos textos que faziam essa alusão, e os que faziam enfocavam vertentes da argumentação diferentes da teoria dialogal. A seguir, serão apresentados alguns dos trabalhos encontrados que versam sobre o tema ora apresentado. Nesse sentido, dentre as pesquisas desenvolvidas sobre o processo de rotulação, 
destacamos aquelas realizadas por Koch $(2006 ; 2011)$ ao estudar a função multifuncional dos rótulos. Embora a autora reconheça uma interligação entre rotulação e os estudos argumentativos, ela o faz sob uma perspectiva diferente da abordada pela argumentação à luz do modelo dialogal. A perspectiva que ela elege aproxima-se dos preceitos da argumentação na língua, desenvolvidos por Ducrot e Carel (1999). Outros pesquisadores seguem o mesmo caminho que Koch, consolidando a relação entre a rotulação, e os demais processos referenciais, com a argumentação inerente à língua.

Carvalho (2005), por exemplo, ao analisar a rotulação em textos opinativos, confirma que os rótulos além de trabalharem na organização textual, constituem-se como operadores de argumentação importantes para a construção de sentido do texto. Essa é a visão compartilhada por Ciulla (2008) ao estudar o processo de referenciação e as suas funções no discurso. Ela acredita que os referenciadores exercem várias funções dentro do texto. Além disso, acredita que essas funções variam de acordo com o contexto discursivo. Nessa linha, Silva (2008), investigou a relação existente entre a referenciação e a argumentação - no sentido da argumentação inerente à língua -, em textos argumentativos, no caso, artigos de opinião. Esse estudo conclui que as expressões anafóricas carregam em sua malha textual a argumentatividade com a finalidade de levar o leitor/ouvinte a um determinado posicionamento. Não obstante, isso é diferente dos postulados do modelo dialogal que se manifesta em diálogos marcados por uma situação de estase (ou conflito) em que surgem perspectivas diferentes sobre o assunto "em questão" (GRÁCIO, 2012, p. 42). Silva (2014) também contribui para o estudo da referenciação, contudo seu corpus é constituído por textos verbo-imagéticos, em que a autora identifica uma preferência pela orientação argumentativa em processamentos referenciais.

Em seu trabalho, Alves Junior (2011), a partir de uma perspectiva sociointeracionista e discursiva de linguagem, em que foram estudados os rótulos presentes em gêneros jornalísticos, atestou que a rotulação é um recurso de coesão que, além de organizar o texto, atua em seu campo semântico e na sua argumentação. Seguindo esse mesmo viés, isto é, de se procurar as ligações entre os processos referenciais e a argumentação - esta vista como uma forma de persuadir e levar o público a determinadas conclusões -, segue o estudo de Sabaini (2012) cuja pesquisa analisa os processos referenciais em textos de cunho argumentativo. Ela evidencia, em sua análise, o papel determinante exercido pela referenciação em textos impressos ao atuar em suas cargas argumentativas.

Outros trabalhos há e que envolvem o estudo da referenciação e da Argumentação: Silva Filho e Rodrigues (2011) abordam a relação entre objeto de discurso e a construção da 
orientação argumentativa; Cavalcante (2016) - foca nas diferentes formas de conceber a argumentação no território da Linguística Textual; Ciulla e Matos (2016) abordam a função avaliativa dos processos de recategorização nas orientações argumentativas; Estevam (2017) preocupa-se com as relações entre referenciação e argumentação, a partir da Nova Retórica de Perelman e Olbrechts-Tyteca; Sales (2017) aborda os processos referenciais e parte de Meyer para tecer reflexões sobre a argumentação; Esteves (2017) enfatiza a função discursiva dos processos referenciais e sua correlação com as relações argumentativas desenvolvidas no texto; Cortez (2018) aborda a relação entre os processos referenciais e a argumentação emocionada; Fumo (2020) limita-se à argumentação e a enunciação na construção textual do sentido a partir da prática pedagógica de ensino-aprendizagem do Português em Moçambique.

Como se observa, a argumentação relacionada com os estudos da referenciação, nos estudos citados, foi vista da perspectiva das orientações argumentativas inerentes ao texto que têm por traço marcante conduzir o leitor/ouvinte a uma determinada posição em relação ao tema discutido no texto. Desse modo, embora os textos falem sobre argumentação, ela está atrelada aos estudos da Linguística Textual sobre argumentatividade e orientação argumentativa, não adentrando, de fato, no campo de estudo da argumentação na perspectiva dialogal e em contexto de interação, apoiados por pressupostos da análise da conversação como se pretende abordar neste artigo.

Por fim, ressaltamos o trabalho de Palumbo (2008, 2013), que busca unir esses dois campos de estudos (Argumentação e Linguística Textual) em suas análises, desenvolvendo instigante estudo sobre a referenciação e a argumentação. Entre os fenômenos da referenciação por ela abordados encontra-se a rotulação. Não obstante outros estudos tenham sido desenvolvidos sobre o campo da referenciação e, nesses estudos, tenha sido apontada sua possível ligação com o campo argumentativo, é com Palumbo $(2008,2013)$ que se pode ver uma tentativa sólida de investigação entre esses campos, mas que, em fim de contas, não aborda a análise à luz do modelo dialogal da argumentação, o que, em fim de contas, ajudanos a justificar a originalidade e relevância da pesquisa que nos propomos a apresentar neste breve espaço, pelas razões já apresentadas.

É nesse contexto que fundamentamos essa pesquisa a partir do modelo dialogal da argumentação e na noção de interação argumentativa nela presentes. Nesse momento, faz-se necessário observar que a argumentação à luz da perspectiva dialogal parte da premissa de discursos em oposição no momento de uma interação argumentativa, construída por participantes ao exporem suas perspectivas sobre um determinado assunto (PLANTIN, 2008; 2018; GRÁCIO, 2010; 2012; 2013; DAMASCENO-MORAIS, 2017; 2020; 2021). 
Essa forma de perceber a interação argumentativa dialoga com estudos de interação sob o prisma da Análise da Conversação (MARCUSCHI, [1986] 2003; KERBRATORECCHIONI, 2006; entre outros). Contudo, enquanto nos estudos conversacionalistas a interação envolvia as situações de diálogo em que os seus participantes interagiam a partir da troca de turnos (SACKS; SCHEGLOFF; JEFFERSON, 1974; FÁVERO; ANDRADE; AQUINO, 1998; BRIZ, 2000; GALEMBECK, 2003; KERBRATORECCHIONI, 2006), na argumentação sob o foco do modelo dialogal a interação que importa é aquela pautada apenas por discursos em oposição, transformados numa questão argumentativa, surgida a partir de uma estase (DAMASCENO-MORAIS, 2020; 2021).

Outro ponto chave neste estudo trata do processo de rotulação (FRANCIS, [1994] 2003; CONTE, [1996] 2003; CARVALHO, 2005; KOCH, 2006, 2011; ALVES JUNIOR, 2011) em que a rotulação é empregada, usualmente, com o intuito de dar encaminhamento ao texto ao conectar e organizar suas partes, ao introduzir e/ou retomar uma informação apresentada e ao acrescentar ao texto uma nova informação (FRANCIS, [1994] 2003; CONTE, [1996] 2003; CIULLA, 2008; CARVALHO, 2005; ALVES JUNIOR, 2011; KOCH, 2006, 2014). Nesse sentido, além dos aspectos referentes ao processo de rotulação e argumentação dialogal, foram convidadas para a discussão algumas categorias da Análise da Conversação. Desse modo, a utilização de algumas categorias e métodos da Análise da Conversa se faz producente e relevante, porque ali o diálogo é colocado como centro e parte do pressuposto de que ele se constitui como uma situação de interação que implica a participação de, no mínimo, dois interactantes que estabelecem entre si uma troca comunicativa (SACKS; SCHEGLOFF; JEFFERSON, 1974; GALEMBECK; SILVA; ROSA, 1990; KERBRAT-ORECCHIONI，1990，2006; MARCUSCHI, [1986] 2003; KERBRATORECCHIONI; PLANTIN, 1995; FÁVERO; ANDRADE,1998; FÁVERO et al., 2010). Esse princípio pode ser compartilhado pela argumentação sob o enfoque do modelo dialogal e que se realiza a partir das trocas comunicativas entre os participantes de uma interação.

Não há dúvidas de que estudar como o processo de argumentação é construído em gêneros da modalidade falada da língua contribui para o entendimento dos processos de interação. Dessa forma, com a intenção de desvelar e compreender mais uma das facetas da interação humana em contexto de interação argumentativa, foi escolhido para análise um gênero que se encontra nessa modalidade citada, no caso, as entrevistas televisivas, especificamente, as entrevistas transmitidas pelo programa Roda Viva, com base em um episódio exibido em 2019. A entrevista tem a duração média de uma hora e vinte minutos e o entrevistado foi o ministro Ricardo Salles (em 26 de agosto de 2019). 
Este artigo está estruturado em quatro blocos: no primeiro, apresentaremos as funções de retomada e antecipação da rotulação; no segundo, falaremos um pouco sobre a interação argumentativa; no terceiro, traçaremos muito brevemente o percurso metodológico realizado na pesquisa; e, no quarto bloco, traremos um rápido recorte analítico sobre a relação existente entre rotulação e interação argumentativa, a partir das funções de retomada e antecipação dos rótulos. E, por fim, encerraremos com as considerações finais, nas quais refletiremos se essa correlação de fato ocorre e se ela se mostra profícua para os estudos no âmbito do texto, da argumentação e da Análise da Conversação.

\section{Rotulação: retomada e antecipação}

O processo de Rotulação insere-se nos estudos da referenciação, que por sua vez encontra-se na área da Linguística Textual (FRANCIS, [1994] 2003; CONTE, [1996] 2003; CIULLA, 2008; CARVALHO, 2005; KOCH, 2006; 2009; 2014; ALVES JUNIOR, 2011). Dito isso, cabe nesse momento deixar claro o que se entende por rotulação como um processo da referenciação. A rotulação, como qualquer outro processo referencial, é um processo em que referentes (objetos de mundo) são construídos discursivamente a partir da percepção social e cultural dos sujeitos decorrente de seus objetivos em momentos de interação. Em outras palavras, a rotulação é uma estratégia da referenciação empregada na construção de referentes (objetos de discurso).

O que diferencia esse tipo de referente dos demais é a sua característica primordial de encapsulador e que dá origem ao termo "encapsulamento" (FRANCIS, [1994] 2003), significado prototípico evoca a ação de compactar, de juntar partes e envolvê-las por uma espécie de invólucro protetor, de empacotar uma parte textual (CAVALCANTE, 2003). E é essa a ideia geral que se pode ter de um rótulo. O rótulo é como uma cápsula que junta partes, no caso, partes textuais, compactando-as em um invólucro conhecido pelo nome de sintagma nominal. Utilizando mais uma comparação, pode-se dizer que esse sintagma nominal, que forma o rótulo, funciona da mesma forma que um rótulo de produtos. Quando alguém vai ao mercado e escolhe o produto que deseja, olha-se para o rótulo dele que geralmente contém todas as informações importantes do produto em um pedaço de papel. Assim, em tese, deve-se ter um apanhado das informações mais importantes do produto de forma resumida.

O que corresponde a dizer é que o rótulo na referenciação funciona de forma semelhante. Ele encapsula uma parte textual, compacta essa parte textual em apenas um sintagma nominal e esse, por sua vez, carrega todas as informações pertinentes da parte encapsulada, funcionando como uma espécie de paráfrase resumitiva (FRANCIS, [1994] 
2003). E é essa característica do rótulo (referente), de resumir uma parte do texto ou ele todo, que o distingue dos demais referentes.

A partir desse conceito, Francis ([1994] 2003) propõe uma divisão entre "rótulos prospectivos" e "rótulos retrospectivos". A diferença básica entre rótulos prospectivos e retrospectivos é que enquanto os primeiros antecedem uma parte textual, os segundos retomam uma parte textual. Isso significa que o rótulo prospectivo, no texto, vem antes da parte que ele encapsula, enquanto o rótulo retrospectivo vem depois da parte que ele encapsula (FRANCIS, [1994] 2003).

Desse modo, chega-se a duas outras funções dos rótulos, a de antecipação e a de retomada de informações, o que permite dizer que o rótulo é informativo, pois ele carrega em si a informação da parte textual que ele encapsula. Além disso, ele também oferece uma nova informação que caracteriza a parte textual encapsulada. Essa divisão básica, feita por Francis ([1994] 2003), é um consenso entre os pesquisadores desse processo (CONTE, [1996] 2003; CARVALHO, 2005; CIULLA, 2008; ALVES JUNIOR, 2011; KOCH, 2006; 2014), os quais compartilham dessa dicotomização do processo de encapsulamento com função de antecipação e de retomada. Essa relação pode ser sintetizada na Figura 1 a seguir:

Figura 1 - Orientação dos rótulos segundo Francis ([1994] 2003)

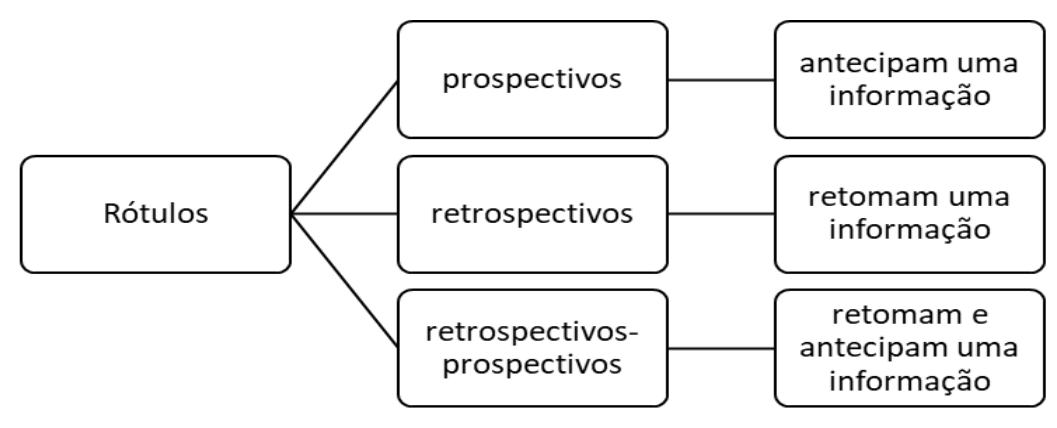

Fonte: Autoria dos pesquisadores.

Na Figura 1 acima, é apresentada a configuração dos rótulos conforme Francis ([1994] 2003). No primeiro segmento, aparecem os rótulos prospectivos que antecipam uma informação que será apresentada a seguir. Esse tipo de rótulo fornece uma orientação de como o leitor/ouvinte deve interpretar a informação que será apresentada posteriormente. No segundo segmento, estão os rótulos retrospectos que retomam uma informação já dada anteriormente e lhe acrescenta um atributo, que pode ser negativo ou positivo. A diferença básica entre essas duas orientações é que enquanto a primeira fornece a interpretação antes mesmo da informação, a segunda fornece a interpretação depois que a informação é 
apresentada. No terceiro segmento, estão os rótulos retrospectivos-prospectivos que exercem as duas funções ao mesmo tempo. Devido a essa característica peculiar, esse terceiro tipo de rótulo quase não aparece no corpus constituído para esta pesquisa. Por esse motivo, aqui se priorizam as duas primeiras orientações.

Em suma, os rótulos, independentemente de sua orientação (prospectiva ou retrospectiva), são objetos do discurso que representam e categorizam o mundo a partir da percepção do indivíduo quanto ao entorno interacional, social e cognitivo em que ele se encontra. Como visto, o fator cognitivo se mostra fundamental nessa abordagem, principalmente na ação de interpretar o que se categoriza. E essa interpretação é motivada pelo cognitivo e pelo social, considerando sua configuração. No próximo bloco será abordada como a configuração dos rótulos se relaciona com esse fator cognitivo e sua relação com o meio discursivo.

\section{Interação argumentativa e o modelo dialogal}

O modelo dialogal da argumentação que, a partir de estudos no campo da Pragmadialética (EEMEREN; GROOTENDORST, 1991) e da Análise da Conversação (SACKS; SCHEGLOFF; JEFFERSON, 1974; MOESCHLER, 1985; GALEMBECK; SILVA; ROSA, 1990; KERBRAT-ORECCHIONI, 1990; 2006; KERBRAT-ORECCHIONI; PLANTIN, 1995; FÁVERO; ANDRADE, 1998; MARCUSCHI, [1986] 2003; FÁVERO et al., 2010), tem sido desenvolvida por Plantin (2008, 2009, 2018), amplificada por Grácio $(2010 ; 2011 ; 2012 ; 2013 ; 2019)$ e atualizada, no Brasil, por Damasceno-Morais $(2017 ; 2020$; 2021), possui como princípio constitutivo a interação e o diálogo, a partir do dissenso ou o que o autor chama de "estase", a qual origina uma "questão argumentativa". O ponto de partida de tal perspectiva é a costura de um discurso e um contradiscurso, a partir do estabelecimento de papéis de atuação: proponente, oponente e terceiro ${ }^{3}$. Tal perspectiva surge com o objetivo de resgatar uma tradição dos estudos da argumentação, uma vez que se baseia em um discurso biface e que tem como base fundamental a interação, a qual surge a partir de uma proposição ou pergunta que se manifesta como uma inquietação sobre algo.

Essa configuração proposta pelo modelo dialogal da argumentação apenas se concretiza caso haja interação e, necessariamente, um assunto em questão. Ali se entende que a interação entre os atores da argumentação, quando gera pontos de vista antagônicos, é fator fundamental para o seu desenvolvimento. Essa perspectiva é corroborada por autores como

\footnotetext{
${ }^{3}$ Damasceno-Morais (2017) no artigo "O redirecionamento dos papéis de atuação em campo jurídico"
} problematiza o papel de atuação "terceiro" e fala sobre um quarto papel de atuação, o "avaliador". 
Grácio, para quem "a noção de assunto em questão (grifo nosso) é, pois, nuclear na compreensão do que se passa nas argumentações vistas como processos que envolvem turnos de palavra” (GRÁCIO, 2012, p. 42). Desse modo, o modelo dialogal de argumentação de Plantin também pode ser considerado um modelo de perguntas e respostas (EEMEREN et al., 2014), assim como, pressupunha a dialética. Por esse motivo, nessa teoria, o diálogo, a partir de uma estase e de uma questão, se torna a pedra-de-toque, pois é através disso (estase $\rightarrow$ questão) que a ação de argumentar se desenvolve.

Grácio, partindo de uma base filosófica, retoma as principais perspectivas de estudos do campo da argumentação de Plantin e, ao mesmo tempo, lança as bases para a sua própria teorização sobre a argumentação. Assim, o autor se apoia em uma perspectiva analítica de base descritivista que, assim como Plantin, concebe a argumentação em contexto interacional e em situação dialogal. Ao trazer uma visão interacionista-dialogal da argumentação, Grácio opta, ao mesmo tempo, por uma visão da argumentação em que argumentar é perspectivar. Perspectivar, para esse autor, é defender um ponto de vista como preferível sobre um assunto que gera diferentes interpretações, visto que "numa argumentação, a questão não é apenas a de avaliar argumentos, mas a de fazer prevalecer perspectivas em confronto com outras perspectivas" (GRÁCIO, 2010, p. 56). A partir dessa problematização, Grácio apresenta uma ruptura com antigos paradigmas, nos quais antes se perguntava a finalidade da argumentação; agora se passa a perguntar o porquê de se argumentar.

E, assim, quando Grácio afirma que não se argumenta apenas para persuadir ou convencer alguém, ele está enfatizando que não se argumentam certezas, pois, segundo o autor, é nas incertezas que a argumentação se desenvolve, porque é nas incertezas que surgem as dúvidas, as interpretações e, consequentemente, respostas diferentes sobre um mesmo assunto. Dessa maneira, mais do que buscar convencer, argumenta-se para se conhecer, para se orientar diante das incertezas. Isso mostra, como afirma Doury (2004), que para definir um discurso como argumentativo é necessário mais do que a possibilidade do surgimento de um conflito. Nesse sentido, partindo de uma ideia que remete, de certa maneira, à "comunhão dos espíritos" de Perelman e Olbrechts-Tyteca,

[...] a argumentação surge, dessa forma, como um modo de gestão da diferença. Essa diferença pode evoluir para diferendo e, de modo geral, esse diferendo pode receber um tratamento não linguístico (eliminação física do adversário; eliminação do discurso do adversário por meio de censura ou de intimidação; sorteio para decidir a próxima ação; voto...) ou um tratamento linguístico, argumentativo (PLANTIN, 2008, p. 74). 
O que interessa a Grácio são as questões relativas ao dissenso, aquelas que surgem quando as interpretações das incertezas são diferentes, provocando um impasse, um ponto de conflito, uma estase, uma tensão entre os discursos. Como visto, nesse sentido, esse autor e Plantin $(2008 ; 2009 ; 2018)$ partilham de uma mesma forma de compreender a argumentação que é vista como "uma atividade custosa, tanto do ponto de vista cognitivo como do ponto de vista interpessoal" (PLANTIN, 2008, p. 64).

A partir dessa tensão se estabelecem contradiscursos. Para Grácio a argumentação se delineia em termos do conflito que surge entre discursos e contradiscursos encabeçados pelos participantes durante a interação. Nesse sentido, para ele, a contra-argumentação pode ser definida como argumentos que se opõem a um discurso. Dessa forma, é o contradiscurso o "ponto de partida" da argumentação e não a apresentação dos argumentos em si. O que retoma a ideia de perspectivação, visto que o objetivo da argumentação se dá em mostrar que certas perspectivas são mais preferíveis a outras. Assim, o estudioso ressalta que uma perspectiva sempre pode ser questionada através da contestação do valor dos seus argumentos. A partir daí, o autor concebe os argumentos como reforçadores de perspectivas.

Plantin e Grácio apresentam a argumentação sob uma ótica integrativa ao trazer para a discussão teorias antecedentes e delas partirem para o desenvolvimento de uma visão da argumentação cuja função não se resuma a persuadir ou a sustentar uma tese. No modelo dialogal, a argumentação é vista como algo que extrapola esses limites, mudando o rumo dos questionamentos, e essa mudança de paradigma constitui a grande originalidade da teoria, pois se muda a perspectiva, o ponto de vista, o foco sobre o objeto, e, por fim, muda-se o próprio objeto.

\section{Marco metodológico: a valorização do processo, não do produto}

Para a realização deste estudo optamos por realizar uma pesquisa qualitativa (GIL, 2002; GERHARDT; SILVEIRA, 2009), por meio da qual o caminho percorrido buscou compreender a função da retomada e antecipação da rotulação na construção argumentativa do gênero discursivo entrevista no programa Roda Viva. Para tal, partiu-se de uma base interpretativista (GIL, 2002; GERHARDT; SILVEIRA, 2009) dos dados e, para que isso se efetuasse, o processo de leitura e fundamentação da pesquisa ocorreu concomitantemente com a seleção e análise dos dados. Esse procedimento foi adotado com a finalidade de realizar uma pesquisa em que o aporte teórico se desenvolvesse a partir dos dados e não o contrário, valorizando o processo e não o produto. 
Dessa forma, ao longo do processo de análise, não se perdeu de vista que haveria a possibilidade de surgimento de novas categorias de análise, o que foi considerado como algo positivo, visto que isso tornou a análise mais dinâmica ao não restringir os dados à(s) teoria(s) proposta(s) e, consequentemente, a mera confirmação de pressupostos teóricos ou afins. A interação e sua dinamicidade é, nesse sentido, um componente da perspectiva teórica que ajuda a compreender a riqueza dos dados selecionados e analisados, isto é, a perspectiva dialogal. E essa dimensão analítica jamais seria possível sem o amparo da Análise da Conversação, que nos auxiliou, sobremaneira, na compreensão da troca de turnos entre entrevistador e entrevistado; na transcrição dos dados e na conscientização de que uma conversa tem regras estrutura e procedimentos próprios.

Assim, definidas as teorias a serem mobilizadas - o processo de rotulação no campo da Linguística Textual e o modelo dialogal da argumentação do campo da Argumentação partiu-se para a seleção e delimitação do corpus. Dessa forma, selecionamos para análise um recorte da entrevista realizada com o ministro Ricardo Salles pelo Roda Viva. Essa entrevista ${ }^{4}$ foi ao ar em 26 de agosto de 2019 com duração de 1 hora e 22 minutos. O entrevistado foi o ministro do Meio Ambiente, Ricardo Salles, que foi entrevistado por Ana Carolina Amaral, Daniela Chiaretti, Giovanna Girardi, Bruno Blecher, Daniel Gallas e pela apresentadora/mediadora Daniela Lima que havia assumido o comando do programa há pouco tempo. O tema central dessa entrevista recaiu na polêmica sobre a preservação ambiental, os incêndios florestais, a suspensão das doações da Alemanha e Noruega para projetos de conservação e a proposta da França para uma discussão internacional sobre o futuro da Amazônia.

Como a entrevista selecionada configura-se tal qual entrevistas televisivas e, como tal, caracteriza-se pela oralidade, fez-se necessária a transcrição dela para as subsequentes análises. Assim, optamos por uma transcrição simplificada, tendo em vista que consideramos para tal apenas os elementos verbais. A partir daí, recortado o corpus e as categorias de análise, o próximo passo foi o mergulho nos dados. Para esse mergulho, foi necessário um longo tempo apenas assistindo a entrevista selecionada, quando se demarcaram os momentos de estase e, ainda, o mapeamento dos rótulos utilizados naquela costura conversacional. A partir disso, foram selecionados trechos em que se faziam presentes as estases e os rótulos, a partir de minuciosa transcrição de dados.

\footnotetext{
${ }^{4} \mathrm{Cf} .:$ https://www.youtube.com/watch?v=QlV3fOz2zto.
} 
A fase final do processo consistiu em analisar a relação existente entre as funções de retomada e antecipação da rotulação com a interação argumentativa e quaisquer comportamentos apresentados por esses elementos. Tudo que foi notado e minuciosamente anotado para futura triagem (DAMASCENO-MORAIS, 2021), na qual foram selecionados os padrões mais comuns: rotulações na construção das estases, rotulação na construção dos pontos de vista e a relação entre rotulação, troca de turnos e papéis de atuação. Desses padrões comportamentais demarcados, selecionamos a relação da retomada e antecipação com o surgimento das estases na interação argumentativa, como veremos, a seguir, no último bloco deste artigo.

\section{Análise do corpus}

O Brasil acabava de passar por um período eleitoral bastante conflituoso, com a opinião dos cidadãos brasileiros dividida entre o apoio e a rejeição ao novo presidente e ao governo por ele instituído. Essa contradição se fez presente inclusive nas escolhas dos ministros. Ricardo Salles, como ministro do Meio Ambiente, foi uma das escolhas do presidente questionadas. Dito isso, a entrevista ocorreu após o primeiro semestre de mandato do novo presidente, marcado desde o início por uma série de questionamentos. Um desses questionamentos foi em relação à situação de desmatamento da Floresta Amazônica cujo posicionamento do governo construiu uma imagem para si mesmo de "lenientes com o desmatamento", imagem agravada com as recentes queimadas na floresta que, devido ao seu volume, provocaram um cenário de crise, chamando a atenção nacional e internacional para o fato. A entrevista com Salles foi realizada diante desse cenário, trazendo essa temática para a discussão. O ministro foi convidado justamente por ser responsável pelo controle e monitoramento dessa situação, tendo em vista seu cargo à frente do Ministério do Meio Ambiente.

A seguir, apresentamos um recorte dessa entrevista no momento do surgimento da estase entre Salles e os entrevistadores. Nesse recorte estão presentes rótulos que exercem a função de retomada e antecipação. $\mathrm{O}$ assunto em questão é tematizado em referência à crise das queimadas na Amazônia, e a estase constrói-se quando Salles é questionado sobre se o governo não seria o responsável pelo agravamento da situação ao adotar uma postura leniente em relação às ações que deveriam ser empreendidas no combate ao desmatamento, às queimadas e na preservação do meio ambiente. 
Excerto 1 - Entrevista com Ricardo Salles

\section{l...l}

RS eu realmente acho que nós precisamos colocar essa questão de maneira muito clara $(+)$ o governo é contra o desmatamento ilegal (+) aliás contra qualquer atividade ilegal é:: praticada por quem quer que seja $(++)$ então nós precisamos de fato é:: deixar isso bastante claro ao explicitar com todas as palavras (+) talvez é:: não tem sido dito da forma mais explícita até então (+) então se não se disse até agora di (+) dizemos já (+) o governo é contra atividades ilegais eu cito um exemplo muito simples que é $(+)$

Como se pode observar, nesse excerto, o entrevistado, exercendo o papel de oponente, nesse momento, constrói sua contraposição e, para isso, utiliza-se de quatro rótulos, dos quais dois exercem a função de retomada e dois a função de antecipação. O primeiro rótulo, "essa questão" (linha 2), faz a retomada do assunto em questão - a responsabilidade do governo quanto ao desmatamento e à crise das queimadas - exposto pelo proponente. Ao fazer essa retomada, o oponente coloca em evidência o assunto proposto e apresenta, em seguida, uma contraposição, que pode ser visualizada nas linhas de 2 a 9, a esse assunto, gerando a estase. Nessa contraposição, ele deixa claro o seu posicionamento em relação à informação referenciada pelo primeiro rótulo ("essa questão"). Enquanto com esse rótulo faz-se a retomada da fala de outra pessoa, no caso o proponente, o segundo rótulo que realiza uma retomada, "essa autorização" (linha 16), designa uma informação expressa na fala do próprio oponente. Essa retomada serve para mudar o direcionamento do seu discurso, indicando ao ouvinte uma pequena mudança de foco no tema abordado.

Os outros dois rótulos utilizados, "um exemplo muito simples" (linha 10) e "a mensagem clara do governo" (linha 22), fazem antecipações que trabalham reforçando o 
posicionamento do oponente que deles se utiliza. Essa ação é realizada pela utilização de um exemplo que sustentará a contraposição do oponente, sendo esse exemplo referenciado pelo rótulo "um exemplo muito simples". Um segundo rótulo é utilizado para reafirmar o posicionamento apresentado e enfatizá-lo, "a mensagem clara do governo". A utilização desses rótulos antecipadamente oferece ao ouvinte um spoiler do que ele deve esperar e, ao mesmo tempo, indica ao ouvinte que ele deve atentar-se para a informação que se seguirá.

Esses tipos de construções podem ser visualizados na seguinte fórmula:

Retomada - assunto em questão < rótulo > assunto em questão [posicionamento] Antecipação - rótulo > ênfase [posicionamento]

Que pode ser traduzida assim: o rótulo exerce a retomada do assunto em questão. Nessa retomada, o posicionamento do interactante em relação ao assunto em questão é evidenciado. O rótulo, ainda, pode realizar uma antecipação. O rótulo utilizado nessa antecipação carrega uma ênfase que atua ao reforçar e evidenciar previamente o posicionamento do interactante. Além disso, vale frisar que a antecipação de um rótulo irá contribuir para indicar previamente como a porção textual rotulada deverá ser interpretada e avaliada pelo ouvinte/leitor, como já apontado no capítulo teórico.

Assim, percebe-se que os rótulos também participam da construção da estase ao retomar e antecipar proposições que carregam o assunto em questão. Essas retomadas e antecipações são estratégias utilizadas como uma forma de direcionar a atenção do ouvinte, de manter em foco o assunto em questão, de enfatizar uma informação importante para a construção da proposição ou contraposição e de indicar um posicionamento.

\section{Considerações finais}

A partir da breve análise que nos foi permitida aqui apresentar, percorreu-se um caminho em que se entrelaçaram perspectivas de estudo distintas umas das outras. Dentre essas perspectivas de estudos, destaca-se o processo de rotulação, inserido dentro da área da Linguística Textual ao abordar os processos referenciais na construção de um texto; e a interação argumentativa, um tipo particular de interação estudada pelo modelo dialogal, desenvolvida por Christian Plantin e ampliada por Rui Grácio, que se encontra, por sua vez, inserida nos estudos da Argumentação. Dessa forma, consideraram-se como centro da investigação aqui empreendida essas duas grandes categorias: rotulação e interação argumentativa, com forte amparo da Análise da Conversação. Esse caminho foi percorrido 
com o intuito de tentar entender as relações existentes entre essas duas categorias, até então, ainda não abordadas, o que reforça a originalidade e importância do estudo ora apresentado, mesmo que não tenhamos tido muito espaço para expansão da análise, o que pretendemos fazer em novas oportunidades de publicação.

Um fato importante a se ressaltar, antes de nossa palavra final, é que, segundo se observou, as funções de antecipação e retomada da rotulação participam diretamente na construção da interação argumentativa, se nos voltamos para o modelo dialogal da argumentação. Isso significa dizer que a rotulação é um processo presente na esfera da referenciação, mas também é um processo da argumentação, nos moldes do modelo dialogal, ou seja, a rotulação se constitui como um processo linguístico argumentativo e interacional, pois participa de forma ativa das interações argumentativas, como tentamos mostrar nesta oportunidade.

\section{Referências}

ALVES JUNIOR, M. A. A estratégia discursiva da rotulação: léxico, argumentação e textualidade. Dissertação (Mestrado em Estudos Linguísticos) - Programa de Pós-Graduação em Linguística, Universidade Federal do Espírito Santo, Vitória, 2011.

BRIZ, A. Turno y alternancia de turno de la conversación. Revista Argentina de Linguiística, v. 16, p. 9-32, 2000.

CARVALHO, M. A. F. O funcionamento textual-discursivo dos rótulos em artigos de opinião. Tese (Doutorado em Linguística) - Programa de Pós-Graduação em Linguística, Universidade Estadual de Campinas, Campinas, 2005.

CAVALCANTE, M. M.; RODRIGUES, B. B.; CIULLA, A. (Orgs.). Referenciação. São Paulo: Contexto, 2003. p. 191-228.

CAVALCANTE, M. M. Abordagens da argumentação nos estudos de Linguística Textual. ReVEL, edição especial, v. 14, n. 12, p. 106-124, 2016. Disponível em: http://www.revel.inf.br/files/ea45a0fb01f8dde37a9435628505a55d.pdf. Acesso em: 22 fev. 2020.

CIULLA, A. Os processos de referência e suas funções discursivas: o universo literário dos contos. $201 \mathrm{f}$. Tese (Doutorado em Linguística) - Programa de Pós-Graduação em Linguística, Universidade Federal do Ceará, Fortaleza, 2008.

CIULLA, A.; MATOS, J. G. Os processos de recategorização na construção avaliativoargumentativa do texto. ReVEL, edição especial, v. 14, n. 12, p. 258-277, 2016. Disponível em:

http://www.revel.inf.br/files/af73ab200876e6eabc0845965c435b90.pdf\#: :text=Al\%C3\%A9 m\%20disso\%2C\%20a\%20nosso\%20ver, \%C3\%A0\%20condu\%C3\%A7\%C3\%A3o\%20argum entativa\%20dos\%20enunciados. Acesso em: 22 fev. 2020. 
CONTE, M.-E. Encapsulamento anafórico. In: CAVALCANTE, M. M.; RODRIGUES, B. B.; CIULlA, A. (Orgs.). Referenciação. São Paulo: Contexto, 2003 [1996]. p. 177-190.

CORTEZ, S. L. Processos referenciais e argumentação emocionada: do pathos à construção do ponto de vista. Organon, v. 33, n. 64, 2018. Disponível em:

https://doi.org/10.22456/2238-8915.81609. Acesso em: 4 mar. 2020.

DAMASCENO-MORAIS, R. O redirecionamento dos papéis de atuação em campo jurídico. In: OLÍMPIO-FERREIRA, M.; GRÁCIO, R. A. (Orgs.). Retórica e Comunicação Multidimensional. 1. ed. Coimbra: Rui Grácio Editor, 2017. v. 1. p. 143-159.

DAMASCENO-MORAIS, R. Dialogando com a perspectiva dialogal da argumentação. In: PIRIS, E. L.; SOARES RODRIGUES, M. G. (Orgs.). Estudos sobre argumentação no Brasil hoje: modelos teóricos e analíticos. Natal: EDUFRN, 2020. p. 143-170.

DAMASCENO-MORAIS, R. O carpinteiro e a madeira: a constituição de corpora jurídicos em perspectiva etnometodológica. Revista de Estudos da Linguagem, v. 29. n. 2, p. 673 709, 2021.

DOURY, M. La position du chercheur en argumentation. Revue Sémen, n. 17, 2004. Consultado em 15 de jun. 2021. Disponível em http://journals.openedition.org/semen/2345.

DUCROT, O.; CAREL, M. Les propriétés linguistiques du parodoxe: paradoxe et négation. Langue Française, Paris, Larousse, v. 123, p. 27-40, 1999.

ESTEVAM, H. Referenciação e argumentação: a construção dos objetos de discurso em textos argumentativos de alunos do Ensino Fundamental II. Dissertação (Mestrado em Educação) - Programa de Pós-Graduação em Educação, Universidade de São Paulo, São Paulo, 2017.

ESTEVES, L. B. Funções discursivas dos processos referenciais de encapsulamento em artigos de opinião. Dissertação (Mestrado em Linguística) - Programa de Pós-Graduação em Linguística, Universidade Federal do Ceará, Fortaleza, 2017.

FÁVERO, L. L.; ANDRADE, M. L. C. V. O. Os processos de representação da imagem pública nas entrevistas. In: PRETI, D. (Org.). Estudos de língua falada: variações e confrontos. São Paulo: Humanitas, 1998. p. 153-177.

FÁVERO, L. L. et al. Interação em diferentes contextos. In: BENTES, A. C.; LEITE, M. Q. (Orgs.). Linguística de textos e análise da conversação: panorama das pesquisas no Brasil. São Paulo: Cortez, 2010, p. 91-158.

FÁVERO, L. L.; ANDRADE, M. L.; AQUINO, Z. G. O. Discurso e Interação: a Reformulação nas Entrevistas. DELTA, São Paulo, v. 14, n. esp., 1998. Disponível em: http://www.scielo.br/scielo.php?script=sci arttext\&pid=S010244501998000300008\&lng=en\&nrm=iso. Acesso em: 3 fev. 2020.

FRANCIS, G. Rotulação do discurso: um aspecto da coesão lexical de grupos nominais. In: CAVALCANTE, M. M.; RODRIGUES, B. B.; CIULLA, A. (Orgs.). Referenciação. São Paulo: Contexto, 2003 [1994]. p. 191-228. 
FUMO, P. P. Referenciação e argumentação no ensino do português em Moçambique. São Paulo: Pontes Editores, 2020.

GALEMBECK, P. T. “O turno conversacional”. In: PRETI, D. (Org.). Análise de textos orais. São Paulo: Humanitas, 2003.

GALEMBECK, P. T.; SILVA, L. A.; ROSA, M. M. O turno conversacional. In: PRETI, D.; URBANO, H. (Orgs.). A linguagem falada culta na cidade de São Paulo. São Paulo: T. A. Queiroz/Fapesp, 1990. p. 45-90.

GERHARDT, T. E.; SILVEIRA, D. T. (Orgs.). Métodos de pesquisa. Coordenado pela Universidade Aberta do Brasil - UAB/UFRGS e pelo Curso de Graduação Tecnológica Planejamento e Gestão para o Desenvolvimento Rural da SEAD/UFRGS. Porto Alegre: Editora da UFRGS, 2009.

GIL, A. C. Como elaborar projetos de pesquisa. 4. ed. São Paulo: Atlas, 2002.

GRÁCIO, R. A. A interacção argumentativa. Coimbra: Grácio Editor, 2010.

GRÁCIO, R. A. Fenomenologia, hermenêutica, retórica e argumentação. Coimbra: Grácio editor, 2011.

GRÁCIO, R. A. Teorias da argumentação. Coimbra: Grácio Editor, 2012.

GRÁCIO, R. A. Vocabulário Crítico da argumentação. Coimbra: Grácio Editor, 2013.

GRÁCIO, R. A. Filosofia da argumentação. Uma arte da hospitalidade voltada para a coexistência: argumentação, contingência e pedagogia da incerteza. Coimbra: Grácio Editor, 2019.

KERBRAT-ORECCHIONI, C. Análise da conversação: princípios e métodos. São Paulo: Parábola, 2006.

KERBRAT-ORECCHIONI, C. Les interactions verbales. Paris: Armand Colin, 1990.

KERBRAT-ORECCHIONI, C.; PLANTIN, C. (Orgs.). Le trilogue. Lyon: Université de Lyon 2, 1995.

KOCH, I. G. V. Rotulação: uma estratégia textual de construção do sentido. Calidoscópio, São Leopoldo, v. 4, n. 2, p. 85-89, 2006.

KOCH, I. G. V. Desvendando os segredos do texto. 6. ed., São Paulo: Cortez, 2009.

KOCH, I. G. V. Argumentação e linguagem. 13. ed. São Paulo: Cortez, 2011.

KOCH, I. G. V. As tramas do texto. 2. ed. São Paulo: Contexto, 2014.

MARCUSCHI, L. A. Análise da conversação. São Paulo: Ática, 2003 [1986].

MOESCHLER, J. Argumentation et conversation. 1985. 
PALUMBO, R. Referenciação e argumentação: a dinâmica nas orientações argumentativas em debates políticos televisivos. Dissertação (Mestrado em Filologia e Língua Portuguesa) Universidade de São Paulo, São Paulo, 2008.

PALUMBO, R. Referenciação, metáfora e argumentação no discurso presidencial. Tese (Doutorado em Filologia e Língua Portuguesa) - Universidade de São Paulo, São Paulo, 2013.

PLANTIN, C. A argumentação: história, teorias, perspectivas. São Paulo: Parábola Editorial, 2008.

PLANTIN, C. Deixem dizer: A norma do discurso de um está no discurso do outro. Revista Comunicação e Sociedade, n. 16, p. 145-161, 2009.

PLANTIN, C. Dictionary of argumentation - an introduction to argumentation studies. UK: College Publications, 2018.

SABAINI, M. T. Os processos de referenciação em textos argumentativos. Dissertação (Mestrado em Letras) - Universidade Presbiteriana Mackenzie, São Paulo, 2012.

SACKS, H.; SCHEGLOFF, E. A.; JEFFERSON, G. A simplest systematics for the organization of turn-taking for conversation. Language, n. 50, p. 696-735, 1974.

SALES, T. Y. N. Processos referenciais em charges de jornais cearenses sob o aspecto multimodal. Dissertação (Mestrado em Linguística) - Universidade Federal do Ceará, Fortaleza, 2017.

SILVA, W. B. A relação entre referenciação e argumentação. Dissertação (Mestrado em Linguística) - Universidade Federal de Uberlândia, Uberlândia, 2008.

SILVA, W. B. A referenciação em textos verbo-imagéticos. Tese (Doutorado em Linguística Letras e Artes) - Universidade Federal de Uberlândia, Uberlândia, 2014.

SILVA FILHO, V.; RODRIGUES, R. H. Referenciação e orientação argumentativa em uma matéria jornalística. Linguagem \& Ensino, Pelotas, v. 14, n. 2, p.503-528, 2011.

VAN EEMEREN, F. H. et al. Handbook of Argumentation Theory. 1. ed. Dordrecht: Springer Reference, 2014.

VAN EEMEREN, F. H.; GROOTENDORST, R. Les sophismes dans une perspective pragmatico-dialectique. In: LEMPEREUR, A. L'argumentation. Liége: Mardaga, 1991. 


\section{Sobre os autores}

Nádia Vieira Simão (Orcid iD: https://orcid.org/0000-0002-5373-1638)

Mestra em Letras e Linguística pelo Programa de Pós-Graduação em Letras e Linguística da Universidade Federal de Goiás.

Rubens Damasceno-Morais (Orcid iD: https://orcid.org/0000-0001-6245-6394)

Professor Doutor em dedicação exclusiva pela Universidade Federal de Goiás (UFG). Integra a linha de pesquisa de pós-graduação Língua, Texto, Discurso (PPGLL/UFG). Membro do Grupo de Pesquisa: Estudos de Linguagem, Argumentação e Discurso ELAD e coordenador do Grupo de Pesquisa Teorias de Argumentação e Retórica (TEAR).

Recebido em maio de 2021.

Aprovado em julho de 2021. 